\begin{tabular}{c}
\hline A SYSTEMATIC REVIEW OF PREVENTION \\
AND INTERVENTION STRATEGIES \\
FOR SMARTPHONE ADDICTION IN STUDENTS: \\
APPLICABILITY DURING THE COVID-19 PANDEMIC \\
\hline Xiao-xia Liu ${ }^{*}$ \\
$\frac{1}{\text { Department of Sports Science, College of Education, Zhejiang University, Hangzhou 310058, }}$ \\
China. 18437956191@163.com.
\end{tabular}

\begin{abstract}
During this coronavirus (COVID-19) pandemic, smartphones play an important role in online classes, study, and entertainment. However, excessive use may lead to smartphone addiction (SPA). The incidence of SPA among students has increased with the spread of COVID-19 and threatens to impair home-based students' learning efficiency and physical and mental health. This study aimed to provide a comprehensive overview of the latest achievements in SPA prevention and treatment, and a theoretical basis for future experimental research and clinical treatment, while considering their applicability during the current pandemic. We researched the core literature in Chinese, English, and Korean databases from 2000 to $2021 ; 3208$ articles were identified. After reading the titles, abstracts, and full texts, 53 articles were selected. Research on SPA interventions was relatively limited; we identified six types of prevention and treatment measures: psychotherapies, cognitive training, behavioral intervention, application restriction, social intervention, and complementary and alternative medicine. They can be implemented by students, parents, or online experts. Future research should focus on developing early measures to identify and prevent SPA and enhance students' change motivation.
\end{abstract}

Keywords: COVID-19; smartphone addiction, students, prevention and intervention, systematic review.

\footnotetext{
* Correspondence concerning this article should be addressed sent to Xiao-xia Liu, Department of Sports Science, College of Education, Zhejiang University, Hangzhou 310058, China.

Email: 18437956191@163.com. Telephone number: 18437956191
} 


\section{A Systematic Review of Prevention and Intervention Strategies for Smartphone Addiction in Students: Applicability During the COVID-19 Pandemic}

The novel coronavirus disease 2019 (SARS-CoV-2 or COVID-19) pandemic has become a major health issue worldwide. In this context, many countries implemented strict control measures, requiring people to isolate themselves at home and go out less often. During this special isolation period, schools around the world implemented online teaching and management, and social media use grew exponentially (Gupta \& DSilva, 2020). Smartphones have thus become an important tool for students to participate in classes, access information, complete homework, socialize, and seek entertainment (van Deursen, 2020; World Health Organization, 2021). However, smartphone use is a doubleedged sword. Excessive smartphone use can interfere with daily life, impair social functioning, and leads to physiological, psychological, and behavioral problems. This phenomenon is known as smartphone addiction (SPA) (Billieux, Maurage, Lopez-Fernandez, Kuss, \& Griffiths, 2015), and also "problematic smartphone use", "smartphone dependency", "smartphone use disorder," and "pathological smartphone use" (Montag, Wegmann, Sariyska, Demetrovics, \& Brand, 2021; Panova \& Carbonell, 2018).

Before the COVID-19 pandemic, there were a staggering 3.3 billion smartphone users worldwide (Statista.com, 2021). According to the 47th report released by the China Internet Network Information Center (2020), China had 986 million users as of December 2020, with students accounting for $21.0 \%$ of the total. In particular, the incidence of SPA among students was in excess of $21.3 \%$ (Long et al., 2016). Moreover, other reports indicate that $10 \%-25 \%$ of Americans exhibit problematic mobile phone usage (Smetaniuk, 2014), whereas $10 \%$ of British students (Lopez-Fernandez, Honrubia-Serrano, Freixa-Blanxart, \& Gibson, 2014) and $16.9 \%$ of Swiss students (Haug et al., 2015) had SPA problems. SPA is becoming increasingly common internationally and has become a serious public health problem (Ding \& Li, 2017; Lopez-Fernandez, 2017). Recently, with the continuous spread of COVID-19, the fear of COVID-19, loneliness and boredom caused by long periods of isolation, and the great temptation brought by the multi-functionality of smartphones, have all led to a significant increase in the proportion of students with SPA (Fung et al., 2021; Han, Nie, \& Lei, 2021; Huang et al., 2021). Latest research shows that the prevalence of SPA among Chinese students increased from $21.3 \%$ to 43.3\% during the pandemic (Zhang, Chen, Tong, Yu, \& Wu, 2021), and other countries and regions also showed varying degrees of increase (Kayis, Satici, Deniz, Satici, \& Griffiths, 2021).

SPA is generally conceptualized as a behavioral addiction including core components of addictive behaviors, such as cognitive salience, mood modification, tolerance, withdrawal, conflict, and relapse (Griffiths, 2005; Kuss et al., 2016; Yen et al., 2009). Many studies have shown that SPA affects an individual's physiological, 
psychological, behavioral, and social functioning (Ding \& Li, 2017). At the physiological level, excessive smartphone use (such as more than seven hours of continuous use) can result in headaches (Milde-Busch et al., 2010), auditory and visual hallucinations (Gong, Chen, Xie, \& Xie, 2019), poor sleep quality (Demirci et al., 2015; Liu et al., 2017; Mohammadbeigi et al., 2016; Xie, Dong, \& Wang, 2018), and pain in the spine, neck, shoulder, elbow, wrist, thumb, neck, and hand (Alabdulwahab, Kachanathu, \& AlMotairi, 2017; Fu, Chen, \& Zheng, 2021; INNal et al., 2015; Shan et al., 2013). Thirty minutes of smartphone radiation can inhibit the functional metabolism of the right prefrontal cortex (Keller, López, \& Moreno, 2015). Exposure to smartphone radiation for 10 hours a day may cause neurological and endocrine dysfunction (Keller et al., 2015), broad changes in gene and protein expression in vitro (Nylund \& Leszczynski, 2006), and negatively affect sperm quality (Redmayne, Smith, \& Abramson, 2011). More seriously, long-term pathological smartphone use is likely to damage the brain's structure and normal functioning (Horvath et al., 2020); for example, the volume of gray matter in the right orbitofrontal cortex (OFC) of SPA patients was found to be lower than that of a normal control group (Horvath et al., 2020). OFC abnormalities can interfere with the decision-making ability, increase impulsiveness (Lee, Brutóoczki, Namkoong, Lee, \& Jung, 2019), and affect brain reward function, emotion processing, impulse control, etc. (Chen, Hu, Lv, \& Long, 2017).

At the psychological level, SPA has been linked to many emotional problems such as loneliness, stress, depression, and suicidal ideation (Hidayati, 2019; Jun, 2016; Santos et al., 2015; Xie et al., 2018), mood disorders (e.g., anxiety, depression) (Demirci et al., 2015), poor memory (Neophytou, Manwell, \& Eikelboom, 2019), concentration issues (Fernandez, Kuss, \& Griffiths, 2020; Ward, Duke, Gneezy, $\&$ Bos, 2017), executive dysfunction (Wang, Tao, \& Xu, 2015), neurodegenerative changes, increased risk of early dementia (Neophytou et al., 2019), family conflict (Chóliz, 2012; Su et al., 2018), and social problems (Ahmed, Qazi, \& Perji, 2011; Chóliz, 2012). At the behavioral level, spending an excessive amount of time on one's smartphone on a daily basis, may lead to academic delays and anxiety, daytime dysfunction, learning ability decrements, and aggressive behavior (e.g., cyberbullying) (Billieux et al., 2015) that adversely affect one's academic performance and career (Grant, Lust, \& Chamberlain, 2019; Liu, Luo, et al., 2020; Rozgonjuk, Saal, \& Täht, 2018; Yang, Asbury, \& Griffiths, 2019). At the social level, SPA is significantly correlated with dangerous driving (Sun \& Jia, 2016) and juvenile delinquency (Grant et al., 2019; Sánchez-Martínez \& Otero, 2009).

Considering the various negative effects of excessive smartphone use, prevention of and intervention for SPA has become a critical issue in fields such as, sociology, psychology, and medicine (Zhang, Chen, \& Du, 2016). Consequently, it is urgent and necessary to review SPA prevention and intervention programs for vulnerable groups such as adolescents and children. However, there is no systematic review process for prevention and treatment of students with SPA. Therefore, this study used the systematic review method to closely examine the influence of 
different treatment methods on SPA. We hope to provide evidence from pre-existing studies, for timely and effective solutions to SPA problems that can be applied to students worldwide during the COVID-19 pandemic. This will, in turn, help them improve their mental, physical, and behavioral health, as well as their social functioning; thereby improving learning efficiency and enriching existing research theories.

\section{Methods}

Major medical, health, psychological, and synthesis literature databases, including Web of Science, ScienceDirect, EBSC, PubMed, Embase, Medline, CNKI, Wanfang, Weip, PsycINFO, and Cochrane database of systematic reviews, from 2000-2021 (until July 2021) were used. The search terms were a combination of " "phone addict_," “phone dependen_," “phone use disorder_," "patholog_phone use," "problem_phone use," "excessive_phone use," AND "intervention," "treat_," "therap_," "prevent_," "program," "precaution," AND "adolescent_," "student_," "children_," etc. The entry style of keywords was modified as required for each database. Using this search procedure, a total of 3208 articles were identified. Upon completion of the search, the titles and abstracts of the identified articles were assessed for their suitability for inclusion in the review. Next, the full texts of the articles that were deemed suitable were retrieved for further examination of the contents. The reference lists of the selected articles were also examined for additional suitable publications that might have been overlooked during the search. The final reviewed sample included 53 articles. The term "phones" in this study primarily refers to smartphones, excluding those without an internet connection.

\section{Results}

Six types of prevention and intervention strategies exist for SPA: psychotherapy, cognitive training, behavioral intervention, application restriction, social intervention, and complementary and alternative medicine.

\section{Psychotherapy}

Psychological intervention refers to methods that identify automatic thinking and false cognition, reduce engagement in dysfunctional activities, establish accurate and rational beliefs, improve supportive adaptive function, and ultimately reduce negative thoughts and addictive behaviors (Han et al., 2018). Common therapies include cognitive behavior therapy, mindfulness-based cognitive therapy, solution-focused brief therapy, peer relationship enhancement program, etc. (Sharma \& Palanichamy, 2018). These can be conducted separately or jointly (de Shazer, 
1985; Kim, 2013; Shonin et al., 2014). A meta-analysis found that psychotherapies can effectively reduce SPA behavior in adolescents, and the effect size value was as high as 1.61 (Han et al., 2018).

\section{Cognitive Behavioral Therapy (CBT)}

Since the 1960s, CBT, proposed by Beck, has been widely used for dealing with a variety of symptoms, and has become the preferred method for treating conditions such as psychological disorders, behavioral addiction, mood disorders, and other psychiatric problems (Hofmann, Asnaani, Vonk, Sawyer, \& Fang, 2012). CBT refers to a short-term method that combines cognitive and behavioral technology to correct adverse cognitions and eliminate negative emotions and behaviors by changing the mode of thinking and behavior (Li \& Shi, 2015). The key mechanism of CBT is to help patients with SPA identify the biased cognitive processes that influence their behavior and decision making, and to shed light on both the process of relapse and the states of mind that leave a person vulnerable to reverting to previous patterns of behavior (Kim, 2013; Li \& Shi, 2015; Orzack, 1999). Thus, CBT can help individuals with SPA establish accurate and reasonable cognitive concepts to replace their original dysfunctional cognitive concepts and wrong assumptions, and limit unhealthy habits and negative emotions.

Studies have shown that CBT is an effective treatment option for SPA that can significantly reduce addictive behavior in children, adolescents, and college students. For example, Park et al.'s (2016) study aimed to investigate and compare the effects of virtual reality therapy and traditional CBT on brain reward circuits and the addiction degree among 24 patients with online gaming addiction. After four weeks of treatment, virtual reality therapy was found to have similar effects as CBT, with both methods reducing the severity of addiction and enhancing the balance of the cortico-striatal-limbic circuit. A recent meta-analysis shows that face-to-face CBT, offered as an individual or a group treatment to teenagers addicted to video games, can effectively reduce online gaming related disorders (Stevens, King, Dorstyn, \& Delfabbro, 2019). Similar to face-to-face CBT, online CBT is also considered to be effective in SPA treatment, and doctors and patients can complete the treatment process using online devices (Okajima, 2015). Thus, compared with the former, online CBT is more suitable to prevent or relieve SPA in home-based students during the current epidemic prevention and control period, as it overcomes the problem of time and place limitations. Additionally, some studies have pointed out that traditional CBT is time-consuming, expensive, requires a considerable number of sessions, and should only be conducted under the guidance of a professional psychological consultant (Austin et al., 2008; Shi, Zhu, Jiang, \& Li, 2017). More importantly, traditional CBT may only superficially modify the smartphone usage time and intensity, fails to address the root causes of the problem, and its benefits are difficult to maintain in the long term (Young, 2009).

Subsequently, on the basis of traditional CBT, Koo (2011) developed a SPA prevention program and tested its effect on middle school students in South Korea. 
The program aims to correct the cognitions of students with SPA; it includes the advantages of correct use of smartphone media and the harmful effects of SPA, and encourages students to establish correct cognitions about smartphones, with the aim of modifying addictive behaviors. In Koo's study (2011), 31 middle school students in the experimental group received the SPA prevention program once a week for 50 mins each. There were 10 sessions in total and the test indicators included selfesteem, self-efficacy, impulsiveness, SPA score, and smartphone use behavior. The students in the experimental group reported a significant improvement in self-esteem and smartphone use behavior compared to the control group; thus, the researcher indicated that the SPA prevention program based on traditional CBT was effective in increasing self-esteem and decreasing SPA in middle school students. However, it is worth noting that there was no significant change in SPA scores in the experimental group after the intervention, and the homogeneity between the experimental group and the control group was low in Koo's study. Therefore, we should be cautious about the intervention effect of the SPA prevention program.

Based on CBT principles, brief CBT (BCBT) has emerged in recent years and has many advantages. For example, the frequency of BCBT is low, generally $2-$ 10 sessions. In terms of content, BCBT usually adopts the most effective steps of CBT for training, in order to eliminate and reduce the use of methods that produce only limited effects (Crawley et al., 2013). It is highly structured and has a detailed therapist's manual (Shi et al., 2017), as well as a patient's treatment manual (Lerma et al., 2016) and parents' reference guide (Beidas, Mychailyszyn, Podell, \& Kendall, 2013). Therefore, BCBT can be administered by experts online, self-administered by the students with SPA, or supervised by their parents. Furthermore, BCBT is easy to learn, is low-cost, and can save medical resources (Crawley et al., 2013).

In conclusion, traditional CBT or new methods of CBT can be performed by experts online or self-administered by individuals with SPA at home during the COVID-19 pandemic period, to prevent and alleviate SPA, and improve their bodymind and behavioral health.

\section{Mindfulness-Based Cognitive Therapy (MBCT)}

MBCT refers to a combination of cognitive therapy and mindfulness-based stress reduction therapy that teaches individuals how to face problems with an open and receptive attitude instead of avoiding current negative thoughts or sadness, through the core techniques of paying attention, being aware of one's physical and emotional states, letting nature take its course, and avoiding judgment (Van Gordon et al., 2017). The key treatment mechanisms of MBCT include two aspects. One is a perceptual shift in the mode of responding and relating to sensory and cognitive affective stimuli that permit individuals to objectify their cognitive processes and to apprehend them as passing phenomena. The other is a reduction in relapse and withdrawal symptoms by replacing maladaptive addictive behaviors with mindfulness (Lan et al., 2018; Shonin et al., 2014). 
Studies have shown that receiving MBCT can reduce the time and frequency of smartphone use by enhancing individuals' attention control, improving their ability to resist the temptations posed by electronic media, and delaying gratification (Jiang, Bai, \& Qi, 2020). For example, Zhang and Zhu (2014) used eight sessions of $\mathrm{MBCT}$ to intervene in 30 adolescent participants, and found that compared to the control group, the SPA level, out-of-control reaction, withdrawal symptoms, and other symptoms in the experimental group were significantly reduced, while their mindfulness level increased considerably, indicating that MBCT had a significant effect on SPA students. Recently, Li, Niu, and Mei (2017) and Jiang et al. (2020) administered an 8-week group MBCT intervention to college students with SPA. The results showed that this intervention method could reduce the SPA detection rate of college students by $66.7 \%$, and also reduce the participants' smartphone use time, SPA level, anxiety level, loneliness, boredom, and impulsiveness. Other research supports this finding (Lan et al., 2018; Zhai, Gai, Jiao, \& Yu, 2016).

Thus, MBCT has been gradually applied in the SPA field and its effects have been recognized. Because MBCT is structured and programed, students with SPA can achieve home-based training with remote guidance from relevant experts in the context of the COVID-19 pandemic, especially mentally immature middle school students. This method can better prevent the extreme behavior and resistance caused by the prohibition of using smartphones and can reduce students' academic anxiety and depression.

\section{Solution-focused Brief Therapy (SFBT)}

SFBT is a kind of short-term psychotherapy and intervention centered on finding solutions to problems (Xu, 2014; Xu et al., 2017). It advocates guiding patients to consider what they can do to end the problem, and unlike traditional psychological counseling, it encourages clients to adopt a positive attitude to solve the problem rather than focus on its cause and guides them to set a change-related goal, making full use of their own resources to do something easy and achievable (Zhao et al., 2009). The consultant helps the patients find and approach their ideal state and establish a motivation for change. Clinical studies by de Shazer et al. (1991) found that in an average of 4.5 sessions attended, about $80.37 \%$ of patients thought that their symptoms had improved, which indicates that SFBT could achieve the goal of improving patients' condition in a small number of consultations. Meta-analyses showed that SFBT has good immediate and follow-up effects on obsessivecompulsive disorder, depression, substance abuse, addictive behavior, and family relationships (Chang \& Nylund, 2013; Gong \& Xu, 2015). Recently, Xu et al. (2017) conducted six-session SFBT interventions for 30 college students with SPA and found significant reductions in SPA severity, inability to control cravings, feelings of anxiousness and being lost, desire to withdraw or escape, productivity loss, and compulsive symptoms, while interpersonal functioning improved. This suggests that SFBT can indeed reduce college students' SPA levels and improve their interpersonal skills and obsessive-compulsive symptoms. 
On the whole, SFBT has the advantages of clear goals, simplicity, and efficiency, and can be used to solve internalizing behavior problems (Xu, 2014). Parents and teachers can reference the ideas and steps of SFBT to help children rebuild a positive cognitive concept aimed toward their future goals, through online or offline behavior change technology (Xu, 2014), thus reducing excessive smartphone use behavior and forming a good behavior pattern during the COVID19 isolation period. However, due to SFBT's consultation process simplification and failure to explore the causes of problems, the resulting consultations may lack depth (Gingerich \& Eisengart, 2000).

\section{Peer relationship enhancement program (PREP)}

PREP is an intervention that encourages students to participate in useful social activities to develop communication, emotional regulation, and social adjustment skills. The therapy includes various games and social skills training for strengthening peer relationships. Kim, Jun, Shin, Lim, and Seo (2018) conducted eight consecutive sessions of PREP for adolescents at risk of Internet addiction and SPA and found that this approach significantly reduced the risk of Internet addiction and SPA, as well as producing major improvements in interpersonal skills and selfesteem. This suggests that PREP can effectively prevent and relieve the risk of SPA in students, thus, parents should strengthen the development of students' social and communication skills. However, few details were provided regarding the program's content, which limits the replicability of the findings (Mac Cárthaigh, 2020). More importantly, because PREP focuses more on reducing physical social distance through engagement in social skills and games to enhance peer interaction opportunities and peer relationship quality and occupies a certain time and frequency of smartphone use to alleviate SPA, home isolation significantly limits the implementation of this intervention. Meanwhile, in the context of the COVID-19 pandemic, the quality of peer relationships declined and did not have the same impact on students' lives as they would have had in school; instead, the relationship with parents became more important (Choi et al., 2021). Therefore, from these perspectives, PREP may be less effective for students with SPA during COVID-19 isolation.

\section{Comprehensive Psychotherapy}

Comprehensive psychotherapy refers to a combination of psychological intervention and other auxiliary measures (Su et al., 2014). Studies have shown that it has a higher success rate in patients with depression, alcohol dependence, and Internet addiction syndrome compared to a single intervention (Riper et al., 2014). For example, Wang et al. (2018) conducted a one-month intervention for 82 college students with SPA by combining MBCT and Naikan cognitive therapy (NCT). NCT refers to a treatment method for correcting irrational concepts by recalling important events in the process of promoting personal growth, experiencing guilt and other negative emotions, and changing one's stubborn self-centered consciousness. The 
results showed significant improvement in tolerance, time control, interpersonal relationships, health, withdrawal reaction, and social comfort in the intervention group. This suggests that comprehensive psychotherapy may have a good therapeutic effect on SPA among college students (Wang, Zhang, \& Kang, 2018). Recently, Zhao et al. (2021) explored the effect of group psychological counseling combined with exercise therapy on psychological craving, addiction degree, depression, and anxiety in 148 college students with SPA. The results showed that three months of exercise intervention alone, group psychological counseling alone, and comprehensive psychotherapy can all inhibit psychological craving, drug addiction, anxiety, and depression in individuals with SPA. Among these, the effect of comprehensive psychotherapy was stronger than for a single intervention mode.

Overall, comprehensive psychotherapy may be effective in reducing SPA levels in college students. In addition, this method also has the advantages of easy operation and low cost, and it causes no harm, making it suitable for implementation during the isolation period.

\section{Psychological education intervention}

Psychological education intervention refers to educational programs and content designed to address psychological problems, which is regarded as the basis and catalyst for cognitive behavioral therapy or other follow-up psycho-social treatments (Zhang et al., 2016). The theoretical framework of psychological education intervention includes identifying the mode of stress and coping methods and the mode of crisis intervention. Recently, Piper, Daily, Martin, and Martin (2020) divided 215 students with SPA into a psychological education intervention group and a control group. After one week, the intervention group exhibited a significantly higher degree of agreement with seven "proper" beliefs about smartphone use and five behavioral domains compared to the control group, thus achieving a small to medium effect. This indicates that a brief psychological education intervention can effectively improve beliefs about smartphones and smartphone use behaviors in individuals with SPA. Although a follow-up study was conducted, only a few individuals participated in the test, and the final measurement was dependent on self-reporting, which lacks objectivity. Further research is needed to examine the longterm effects of this intervention.

\section{Cognitive Training}

\section{Inhibition Control Training}

Inhibition control training refers to the ability to suppress ongoing or planned motor or cognitive processes and enable the process of adapting to a rapidly changing situation (Ding, $\mathrm{Zu}, \&$ Zhang, 2018). The essence of this intervention is to train and improve the inhibitory control ability of patients with problem behaviors, which may involve two main mechanisms: the development of automatic forms of 
inhibition, or the strengthening of top-down, controlled inhibition (Spierer, Chavan, \& Manuel, 2013).

Lack of inhibition control ability is related to a variety of addictions and problem behaviors (D'Hondt, Billieux, \& Maurage, 2015). Out-of-control smartphone use is also one of the main characteristics of individuals with SPA (Jameel, Shahnawaz, \& Griffiths, 2019). Enhancing inhibition control skills in students with SPA is an effective method to reduce pathological smartphone use. Previous studies have usually used the go/no-go paradigm and the stop signal task paradigm to improve inhibition control ability and showed a positive effect (Spierer et al., 2013). For example, Ding et al. (2018) adopted the go/no-go paradigm to conduct inhibition control training (four weeks, twice a week, 40 minutes/session) for 28 Chinese college students with SPA, and the results showed that, compared with the control group, the SPA score and smartphone usage duration of the experimental group were significantly reduced, and the inhibitory control ability was significantly improved. The effect was maintained for about three months after training, possibly because the training improved automatic and top-down control inhibition, induced changes in the relevant brain areas, and promoted the recovery of inhibition control ability (Lawrence et al., 2015). This suggests that inhibition control training may be an effective intervention for SPA; however, because of the limited evidence at present, more experimental studies are needed.

\section{Attentional Bias Training (ABT)}

ABT is a systematic training program designed to correct the early attentional processes of individual with SPA, which can enhance attention control ability and reduce cognitive and emotional disorders (Beard, Sawyer, \& Hofmann, 2012). At present, ABT consists of multiple paradigms, such as the dot-probe paradigm and the visual search task (Leeman, Robinson, Waters, \& Sofuoglu, 2014). Dot-probe training (MacLeod \& Clarke, 2015) is the most frequently used ABT paradigm. The mechanism of ABT is that it can change cognitive processes by inducing an individual to repeatedly select positive or neutral stimuli, while continuously disengaging attention from threatening stimuli (Liu, Wang, Zhou, \& Cai, 2020).

Chen et al. (2017) conducted ABT based on the dot-probe discrimination paradigm for the first time among 40 students with SPA; eight sessions were conducted over two weeks and the assessment methods included a self-reported SPA scale. The results showed a significant decrease in the overall SPA, withdrawal symptoms, salient behavior, and mood alteration in the training group in both the post-test and the four follow-up assessments. This shows that ABT can successfully guide students with SPA to pay more attention to positive stimuli and thereby effectively reduce attentional bias and SPA tendencies. Furthermore, the training effect is stable (Chen \& Yu, 2017). However, the researchers did not examine whether ABT had an actual effect on the participants' attention control ability and behavior. Borkenau and Liebler (1993) noted that self-reported data may differ from 
behavioral and physiological parameters. Recently, Liu et al. (2020) also adopted ABT based on a dot-probe discrimination paradigm to train 16 college students with SPA once a day for six consecutive days, with assessment indicators that included quantitative and qualitative analysis. The results showed that smartphone usage duration, attention deficit, and SPA level of the experimental group were significantly reduced, and the emotion regulation ability was marginally improved. Meanwhile, $75 \%$ of the ABT group no longer met the criteria of SPA, compared with $46 \%$ of the control group. This indicates that ABT was an effective intervention for SPA.

Overall, computerized inhibition control training and ABT designed to reduce SPA have shown promising results. The advantages of cognitive training are its low cost and high repeatability without the limitations of time and space. Students with SPA can operate independently by remote guidance of experts, or they can be supervised by their parents and teachers after learning how to operate the program, which is especially suitable for the current COVID-19 isolation period.

\section{Behavioral intervention}

\section{Exercise Therapy}

As an intervention method for problem behavior, exercise therapy can broadly solve individual physiological and psychological problems, while also reducing SPA. This therapy can relieve individuals' loneliness, stress, anxiety, and other negative emotions through the sense of pleasure obtained from physical activities, divert attention from smartphones, and utilize the time usually spent on smartphones to indirectly affect addictive behavior, producing quick and effective results (Kim, 2017). In addition, physical exercise can also relax and adjust overexcited nerves, strengthen the functioning of neurohumoral regulation and the central nervous system, and improve adaptability to external stimuli (Ge, Zhong, \& Chen, 2015).

Ge et al. (2015) found that after 18 weeks (three times a week, 2 hrs per session) of a volleyball exercise intervention, smartphone usage duration and addiction index of the individuals with SPA were significantly lower than those of the control group; negative emotions were reduced, while self-confidence, interpersonal communication skills, and learning efficiency were improved. Bu's (2014) study adopted a comprehensive intervention method of physical exercise with an exercise intensity of $60 \%-80 \%$ HRmax for more than 30 min per session, 3-5 times a week, combined with mental health counseling. The results indicated a reduction in the smartphone usage time and SPA levels of college students, and improvement in SPA-related symptoms. Participating in exercise can help users with SPA internalize appropriate values, experience the joys of life, get away from the virtual smartphone world, and develop a positive and enterprising spirit ( $\mathrm{Bu}, 2014)$. Recently, a literature review on the association between physical activity in student groups and SPA found that SPA can be reduced by increasing participation in sports 
and involvement in physical activity/exercise (Azam, Ali, Mattiullah, \& Perveen, 2020).

Although exercise interventions are generally effective, there are boundary conditions. For example, Wang and Zhang (2016) showed that exercise intervention can significantly improve mild and moderate SPA symptoms of medical students, but the exercise therapy has less effect on individuals with severe SPA. The reason for this difference is that patients with severe SPA have risen to the degree of pathology (weak self-control), and exercise therapy mainly reduces the dependence on smartphone by adjusting the daily habits of patients with SPA and regulating physiological indexes, rather than solving the problem from the perspective of patients' cognition. Meanwhile, taking part in sports regularly over a long period requires strong self-control and external supervision, and its persistence is easily disturbed by other irrelevant factors. Once the external supervision force is weakened or self-control is reduced, the effect of exercise therapy on SPA may become poor or even ineffective (Wang \& Zhang, 2016). Similarly, a meta-analysis by Han et al. (2018) found that the effect of exercise therapy on SPA individuals was not significant, and the researcher attributed this to the limited number of only three intervention-related articles and their poor quality (Han et al., 2018).

Overall, the current results on whether exercise therapy can reduce SPA are not completely consistent; exercise has been proven to have benefits for physical and mental health, emotional states, the nervous system, and cognitive functioning of people with different addictions (Huang, Zheng, Gao, Hu, \& Yuan, 2020). Due to the advantages of low-cost, easy operation, easy promotion, and independent training, exercise therapy is also suitable for the special period of COVID-19 isolation. Schools and classes can organize online remote physical education teaching activities and ensure interactions between teachers and students, to inculcate sports and exercise related habits and attitude in students, using cloud video and video supervision of students doing moderate exercise, such as yoga, Pilates, aerobics, taijiquan, etc., thereby promoting students' adaptive use of smartphones.

\section{Pre-Bedtime Intervention}

Bedtime intervention refers to a behavioral intervention that restricts students' smartphone use to one hour before sleep (Bartel, Scheeren, \& Gradisar, 2019). Smartphone use is associated with delayed bedtimes among adolescents, potentially leading to less sleep as the phone use increases (Bartel, Gradisar, \& Williamson, 2015). Lack of sleep at night leads to concentration issues and reduces daytime learning efficiency (Chen, Lou, Zhang, \& Liu, 2019). In contrast, increased sleep duration is correlated with better cognitive performance in adolescents (Dewald-Kaufmann, Oort, \& Meijer, 2013). Bartel et al. (2019) adopted individualized phone stop times, one hour before bed for one school week. An online sleep diary was used to monitor bedtime, lights out time, sleep latency, and total sleep. The results showed that the adolescents who participated in the intervention had better sleep quality. Specifically, during the one week of phone restriction, the 
adolescents stopped using their phones earlier and turned their lights off earlier, so that their total sleep duration increased (Bartel et al., 2019). This indicates that prebedtime interventions have many potential benefits for SPA. However, many adolescents lack the motivation to negotiate changes in their evening phone use (Bartel et al., 2019). Further research is needed to identify non-technological interventions to increase adherence to phone restriction (e.g., motivational interviewing) or otherwise decrease pre-sleep arousal (e.g., cognitive strategies) (Bartel et al., 2019). In conclusion, during the epidemic prevention and control period, parents should strictly limit SPA children's smartphone use to one hour before bedtime, which will improve the students' physical-psychological health and learning efficiency.

\section{Application Restrictions}

Due to the limitations of traditional clinical surveys and interviews, especially during the COVID-19 epidemic period, it is difficult for professionals to perform continuous long-term quantitative assessment and intervention on students with SPA. To overcome these limitations, researchers have developed some smartphone application-based interventions that do not require facilitation by healthcare professionals. Instead, they can be operated independently by families or users themselves. Additionally, application restrictions may be a cost-effective way to reduce a student's SPA during COVID-19 (Mac Cárthaigh, 2020).

\section{SPA Management System (SAMS)}

Lee, Ahn, Choi, and Choi (2014) developed a comprehensive ICT system called SAMS for objective assessment and intervention of SPA. SAMS consists of an Android application and a web application server. The SAMS client can monitor the user's application usage, as well as the GPS location and Internet access location, and transmit the data to the SAMS server. The server diagnoses the SPA level according to the user's daily smartphone usage duration and frequency and provides a corresponding analysis. Meanwhile, it can also provide the user's clinician with recommendations on prevention and treatment, such as setting a smartphone limit function. When the time spent playing a game exceeds the designated usage time, the SAMS client will generate a pop-up prompt message and prevent the user from continuing to play the game, which may be very suitable for primary and secondary school students. The advantage of SAMS is that it can record smartphone usage objectively and quantitatively, provide accurate diagnosis, maintain long-term treatment, and prevent relapse of addiction at different stages. SAMS has been shown to be effective in the long-term treatment of addiction, diabetes, and obesity (Gustafson et al., 2011). Lee et al. (2014) also believed that SAMS is very useful for SPA treatment. However, due to the small sample size and lack of control group in this study, the generalizability and application of SAMS are limited (Lee et al., 2014). Further research is needed to verify its effectiveness in treating SPA. 


\section{No Use is Good Use (NUGU)}

NUGU refers to a group-based usage mediation intervention for improving self-regulation of and limiting smartphone use, by leveraging social support: groups of people limit their smartphone use together by sharing their limiting information. NUGU is designed based on social cognitive theory, which emphasizes the leverage of social support and competition to modify problematic behavioral patterns (Bandura, 1991). NUGU consists of three components: (1) self-monitoring, (2) goalsetting, and (3) social learning and competition. Each component is designed to support three sub-processes of self-regulation from the social cognitive theory perspective, that is, self-monitoring, self-judgment, and self-reaction. NUGU solves these issues by visualizing objective usage/limiting behaviors, setting limiting goals, sharing limiting practices, and reinforcing desirable behaviors. NUGU can improve self-regulation and limit smartphone use, thus mitigating SPA among adolescents (Ko et al., 2015).

Ko et al. (2015) used a three-week NUGU program to intervene with 62 users. The measurement methods included quantitative and qualitative indicators: 1) a logger assesses the total smartphone usage duration and the number of app executions; 2) the scale was used to assess the severity of SPA; 3 ) the user's selfefficacy of self-regulation of smartphone use is measured; 4) exit interview assesses which NUGU's design elements are effective. The results showed that NUGU-Group users' usage duration and number of app executions decreased significantly as they started to use the intervention app. The study provided a relatively comprehensive assessment of NUGU. However, this study has shortcomings such as small sample size, short intervention time, and lack of randomization in the allocation of participants. Therefore, future longitudinal, large-scale, and randomized trials with participant allocation are needed to provide stronger evidence regarding the effectiveness of NUGU.

\section{FamiLync}

FamiLync is a mobile device-based application that facilitates participatory parental mediation to curb excessive smartphone usage among adolescent children and their parents (Ko, Choi, Yang, Lee, \& Lee, 2015). Similar to NUGU, the application also draws upon social cognitive theory (Bandura, 1991), which holds that ameliorating excessive mobile device usage is best achieved through cooperative and communicative learning (Ko et al., 2015). Important application features include the facilitation of increased awareness about the usage patterns of the individual and the whole-family through objective feedback (frequency and duration), goal-based use limiting, and collaborative rule-setting (Mac Cárthaigh, 2020). Ko et al. (2015) evaluated the effectiveness of FamiLync on 35 users for three weeks, and quantitatively and qualitatively investigated changes in parental mediation of smartphone usage after FamiLync use. Results showed that the family members could better recognize their usage patterns with FamiLync's self- 
monitoring support. FamiLync improved the mutual understanding of usage patterns and facilitated discussions on each member's smartphone usage, which provided common grounds for usage intervention. Furthermore, the study found that parents typically allowed their children increased independence in terms of smartphone usage (e.g., use location and content type), and actively participated in limiting smartphone use with their children, which significantly motivated the children's continued participation. Overall, FamiLync significantly reduced smartphone usage and facilitated improvements in parent-child interaction and parental mediation of smartphone usage. However, there is a fundamental tension between visibility and privacy and therefore, the system design should also deal with the asymmetry in physical capability and technology competence to elicit more participation. In addition, having been carried out at a single site, the generalizability of this research is relatively limited. Therefore, further research in different schools and cultural environments comprising students and parents from various socio-economic backgrounds is required.

\section{Lock n' LoL}

Lock n' LoL is an application designed to help users focus on their group activities by allowing group members to limit their smartphone usage together (Ko, Choi, Yatani, \& Lee, 2016). In particular, it provides synchronous group awareness that all members are currently limiting their smartphones during a group activity. This synchronous limiting feature is motivated by the fact that an individual's smartphone usage can influence others' behaviors. For example, it is likely that the other members are tempted to engage in their phones or are distracted by other activities. Ko et al. (2016) conducted an intervention on 976 users using Lock n' LoL and the results showed that all the users had 10,365 hours of smartphone restriction during the campaign over 25 days. Furthermore, $44.6 \%$ of the 976 users showed at least two hours of use limiting, and the mean duration of use limiting per user was noted as 91.4 minutes per day. This suggests that Lock n' LoL may help reduce smartphone distraction and reduce smartphone use behavior. Peer pressure is a powerful factor to encourage people to limit smartphone use in group activities, but this may depend to a large extent on their willingness to limit. For example, many people are afraid of missing out on important information when limiting smartphone usage or have privacy concerns arising from usage logging, so it is difficult to maintain the limitations on use. Recently, Mac Cárthaigh's (2020) systematic review affirmed and recommended the usage restriction function based on mobile devices or applications. He pointed out that this method can reduce smartphone use without the assistance of health care personnel but with the supervision of family members or friends, making it a cost-effective way to reduce a student's SPA during COVID-19.

In summary, application-based SPA interventions include SAMS, NUGU, FamiLync, and Lock n' LoL, all of which leveraged the need for social validation and powerful reinforcement of notifications to encourage mobile device use-limiting behaviors. Currently, there is a lack of online treatment/intervention programs for 
SPA. The novel idea of online therapy through mobile device-based applications is considered groundbreaking research in this field (Mac Cárthaigh, 2020). These approaches show positive potential to treat SPA, which will provide a broader approach for the treatment and management of SPA behavioral problems during the COVID-19 pandemic. However, it should be noted that these therapy programs are mainly technologically driven, not based on or derived from a sound conceptualization of the etiology, trajectory, or progressive development, and clinical manifestations of the problem, and tend to ignore the psychological or emotional state of the student with SPA. This may, in turn, affect the efficacy and effectiveness of these therapies in addressing the issue of SPA.

\section{Social Intervention}

\section{Health Educational interventions}

Health education intervention refers to a planned learning process in which individuals, groups, and communities acquire relevant knowledge and skills to make correct and healthy choices based on theoretical guidance (Lan, 2019). Smartphone use attitudes and behaviors can be modified in the short or even the long term, which may be of particular interest to mental health providers with patients, or their family members interested in reducing SPA (Zadeh, Changizi, \& Sadeghi, 2014). The best approach for preventing addictive behaviors is the promotion of knowledge, attitudes, and beliefs (Zadeh et al., 2014). One of the most commonly used health education models used for the prevention of addictive behaviors is the Health Belief Model (HBM) (Ahmadi Jouybari et al., 2018; Ghaderi et al., 2017; Khani Jeihooni et al., 2018; Luquis \& Kensinger, 2019). It consists of six constructs: a. perceived susceptibility, b. perceived severity, c. perceived benefits, d. perceived barriers, e. cues to action, and f. self-efficacy. An earlier study reported that the HBM constructs are potentially useful for controlling and preventing Internet addiction (Wang, $\mathrm{Wu}$, \& Lau, 2016).

Recently, Khoshgoftar, Amidi Mazaheri, and Tarrahi's (2019) study examined the effect of an educational intervention based on the HBM to prevent SPA among female high school students. Professional trained educators in the SPA field gave lectures and helped students with SPA build a correct concept of smartphone use through group discussion, movie watching, role playing, questions and answers, lectures, and other means. The education intervention lasted for two months, with six sessions in total and each lasting 60-90 minutes. The results showed that the participants' susceptibility, perceived severity, and self-efficacy were significantly improved, and SPA levels significantly decreased, indicating that an educational intervention based on the HBM can effectively prevent and decrease students' SPA (Khoshgoftar et al., 2019). Inconsistent with the above research results, Choi (2015) conducted an 8-session health education intervention on 26 individuals with SPA over four weeks and found that compared to the control group's participants, the experimental group's participants knowledge about SPA 
was significantly improved. However, their attitude towards SPA did not improve greatly.

Overall, health education intervention is one of the promising ways to treat SPA. However, to change perceived benefits/barriers or attitudes, it is not enough for students with SPA to have an educational intervention; their family environment and socio-cultural structure also need to change. During the COVID-19 epidemic period, in addition to a health education curriculum that can be modified to be completed online, there is also a need to let parents with children participate in and accept online health education training, and transform their own smartphone behavior and concepts, to help children absorb the importance of correct use of smartphones, and experience healthier forms of entertainment.

\section{Environmental Intervention}

Family, school, and society are the three most important domains in the life of students of all ages. Individual or coordinated intervention among them is collectively referred to as environmental intervention, which is a kind of implicit intervention (Zhang, Xiao, \& Zhu, 2019).

At the family level, the parent-child relationship plays an important role in alleviating SPA. Particularly during the COVID-19 period, the impact of family relationships on the physical, mental, and behavioral health of students became more important than ever before (Choi et al., 2021). Parents' attitude, family communication, family cohesion, and family well-being are all important protective factors in determining adolescent behavioral addiction (Guo et al., 2019; Wei, Zhou, Zhang, \& Ding, 2018). A good parent-child relationship can not only provide children with a sense of security and a positive communication channel, but also satisfy their psychological need for close relationships, which can help them avoid overusing smartphones to reduce loneliness and escape motivation. It also helps monitor children's daily behavior, reduces the frequency and time of smartphone use, and protects against pathological cell phone use (Zhen, Liu, Hong, \& Zhou, 2019). Therefore, parents should provide humanistic care, take the initiative to communicate with the child, show practical understanding of their feelings, and praise and encourage them. In addition, leisure activities have a buffering effect against the pressures of daily life (Zhen et al., 2019). Research shows that people at high risk of gaming addiction have less time for family leisure activities than those with a low risk (Kim, 2013). However, $65.3 \%$ of youths with gaming addiction want to participate in family leisure activities. Surprisingly, students who are rich or have highly educated parents are also more likely to be addicted to gaming (Kim, 2013). Therefore, parents should frequently organize active and healthy family leisure activities to meet the children's inner desire for entertainment and need for affection, which can be effective in preventing and alleviating students' SPA.

At the school level, teachers and school leaders of all classes should regularly set up online psychological health education courses and lectures, establish rules and regulations, and provide education and supervision so that students can 
enhance their awareness about prevention measures (Jia et al., 2018). At the social level, the relevant government departments should establish and improve the network's legal system, increase censorship of information websites, and resolutely curb the spread of disinformation (Nie \& Liu, 2014). Smartphone software operators should also commit to vigorously purifying the smartphone network environment (Zhang et al., 2016) and focusing more on promoting learning resources, inspirational stories, learning methods, and enjoyable intellectual games to students instead of idle dramas and violent games. In general, different countries and regions can establish a tripartite linkage mechanism of family, school, and society to prevent and reduce the occurrence and development of students' SPA problems.

\section{Complementary and alternative medicine (CAM)}

CAM refers to non-mainstream treatments that are either used in addition to, or in lieu of, conventional treatment (Aletraris, Paino, Edmond, Roman, \& Bride, 2014). These include diverse treatments, such as music therapy (MT), art therapy (AT), hypnotherapy, and acupuncture. Recently, the use of CAM has rapidly increased in the field of disease control and prevention ( $\mathrm{Su} \& \mathrm{Li}, 2011)$, especially in case of substance abuse disorders (Hohmann, Bradt, Stegemann, \& Koelsch, 2017). Only one known SPA study mentioned MT and AT (Kim, 2013), which may work as effective supplements to SPA treatment in the future.

\section{MT}

MT is defined as the "clinical and evidence-based use of music interventions to accomplish individualized goals within a therapeutic relationship by a credentialed professional who has completed an approved music therapy program" (Hohmann et al., 2017). MT can use songs and melodies to enable patients to express emotions, motivations, and barriers to recovery (Hohmann et al., 2017). Compared with traditional forms of communication, MT can better help patients to tap into their emotions and needs (Aletraris et al., 2014). It has a beneficial impact on mood (Shuman, Kennedy, DeWitt, Edelblute, \& Wamboldt, 2016), stress (Pelletier, 2004), motivation (Ross et al., 2008), and emotional expression (Baker, Gleadhill, \& Dingle, 2007). Neuro-imaging studies have demonstrated that music listening engages many brain structures important for cognitive, emotional, and sensorimotor processing (Koelsch, 2009), in particular the mesocorticolimbic system (Zatorre, 2015). Moreover, drumming circles in MT have an important role as a complementary therapy, particularly for relapses and when other counseling modalities have failed (Kim, 2013). Drumming activities can promote recovery by inducing relaxation and enhancing theta-wave production and brain-wave synchronization. Furthermore, they alleviate self-centeredness, isolation, emotional trauma, and alienation, creating a sense of connectedness with self and others (Kim, 2013). MT can be performed without a music therapist or other individuals therapeutically guiding the music intervention, which is called music presentation 
(Hohmann et al., 2017). Although there are no experimental studies to verify the role of MT in SPA, during the COVID-19 pandemic, students in home-based isolation can still try MT, such as drumming circles.

\section{AT}

AT can help patients express themselves through non-verbal, imaginative, and creative exercises, involving a range of activities, such as incident drawings, drawing/painting emotions, stress painting, creating an art journal, and creating sculptures (Aletraris et al., 2014). Similar to MT, AT also plays an important role in managing addictions (Aletraris et al., 2014). For example, Park, Kim, Lee, \& Kim, (2009) applied AT to juvenile gaming addiction to improve self-control techniques. The results showed a decrease in hostility and an increase in social interaction with peer groups and family members. In the COVID-19 period, AT may also exert promising therapeutic effects for controlling SPA.

\section{Discussion}

\section{Future Directions}

Smartphones are a double-edged sword (Yu \& Liu, 2019). They can be used as an effective tool for obtaining information and communicating with others during the epidemic (van Deursen, 2020). In this respect, preventing SPA will increase the likelihood of using smartphones as an effective tool to cope with the epidemic, making it easier for individuals to obtain information about COVID-19, and take precautions; it can be an effective aid for communication in isolation conditions, which can help facilitate good individual mental well-being (van Deursen, 2020). Meanwhile, smartphones play an important pedagogical role (Cochrane \& Bateman, 2010), especially during the current pandemic, allowing students to take classes online, overcoming the time and space limitations (Hu \& Xie, 2020). Thus, when smartphones are used effectively, they promote the development of social relationships and wellbeing.

However, chronic smartphone overuse can develop into SPA (Körmendi, Brutóczki, Végh, \& Székely, 2016). SPA has been shown to be an international phenomenon and mitigating excessive mobile device usage among students is a formidable challenge (Lopez-Fernandez, 2017). Research should be conducted on how to provide remote services to reduce threats to the physical and mental health of students with SPA during the pandemic (Torous \& Keshavan, 2020; Torous, Myrick, Rauseo-Ricupero, \& Firth, 2020). Unfortunately, to date there has been no comprehensive systematic review of SPA prevention and treatment. This current review therefore provides a necessary comprehensive overview of interventions applicable to SPA, which can be divided into six categories: psychotherapies, cognitive training, behavioral intervention, application restriction, social intervention, 
and complementary and alternative medicine. During this pandemic control period, students can choose appropriate methods according to their own situation, operated online by experts, implemented under the guidance of parents, or by the students themselves. However, research on the prevention and treatment of SPA is limited at present (Kwon et al., 2013; Zhang et al., 2016), so expansion of the current body of research is necessary. The following suggestions can be considered for future research.

First, studies so far have mostly used psychological and behavioral interventions (especially exercise therapy) to treat SPA, while the evidence for other interventions is limited. For instance, educational interventions were used in only one study (Khoshgoftar et al., 2019), while MT and AT were only mentioned and not tested in experimental studies (Kim, 2013). The effectiveness of different interventions remains to be demonstrated. Existing studies have showed that a combination of multiple interventions may be more effective than a single intervention (Manning et al., 2019). Combined intervention can be employed to maximize the prevention or alleviation of SPA among students and achieve lasting and beneficial effects. Second, the average age of individual smartphone users is decreasing, which has many negative effects on children and teenagers (Bian \& Leung, 2015). However, compared to the research on the causes, influencing factors, and harmful effects of SPA, research on SPA prevention and treatment is scant (Jiang et al., 2020). Furthermore, the experimental subjects of most studies have been college students. Future research should pay more attention to intervention measures to identify and prevent teenagers' and children's SPA tendencies, to curb the development of SPA before addiction occurs, and reduce physical and mental health damage.

Third, assessment of SPA severity, smartphone usage duration, and intervention effects are mainly based on surveys and interviews, and the methods are simple and subjective, which may lead to errors in measurement (Lee et al., 2014). Therefore, objective and quantitative usage needs to be recorded to conduct diagnoses and apply treatments based on concrete and accurate data. The equipment or software time and frequency records can be used to objectively measure compliance, such as the free application screen on/off logger. In addition, many studies have tracked immediate effects and found that smartphone usage decreased after the intervention. However, future research needs to include follow-up evaluations to examine if the effectiveness has been maintained long-term. Fourth, lack of motivation is a key problem in SPA treatment. Many students may lack motivation to reduce their smartphone usage, which can lead to low engagement, high dropout rates, or poor intervention effects. An important direction for future research is to identify and strengthen students' motivation to change before an intervention, such as adding motivational interviews and cognitive strategies, to maximize the intervention effect of different methods. Finally, future research needs to differentiate between SPA types, such as social networking, gaming, or video addiction. Different prevention and treatment programs can be designed for different types. 


\section{Limitations}

This study has several limitations. First, because of the limited research evidence for different intervention methods, most of which were conducted in laboratory environments, the present review does not provide clear evidence about the training effect for students at home. Second, we reviewed the SPA intervention methods mentioned in the core literatures of the past 21 years as comprehensively as possible, and the literature retrieval languages were Chinese, English, and Korean, among others, which may have led to incomplete retrieval.

\section{Implications}

One aim of schooling is to foster the healthy growth of adolescents (Chen, Lin, \& Liu, 2020). The current article serves as a discussion guide to provide school nurses, clinicians, and teachers with several possible appropriate interventions to diagnose and intervene in students' pathological smartphone use. More importantly, there are some interventions that can be operated not only face-to-face, but also online, such as computerized ABT (Sportel et al., 2013), which means that healthcare providers can be involved in the development and use of remote ABT to help homebased students with SPA during the COVID-19 pandemic. These types of training can overcome the limitations of time and space and thus reduce the risk of viral infection associated with leaving one's home for treatment.

\section{Conclusion}

This study systematically reviewed various ways of preventing and intervening in SPA. The process of prevention and intervention in SPA is still in the preliminary exploration stages, and there is an urgent need to design and implement more appropriate interventions to reduce and prevent addiction.

\section{Conflict of Interest}

The author declares no conflict of interest.

\section{Acknowledgments}

We would like to thank Editage (www.editage.cn) for English language editing. 


\section{References}

Ahmadi Jouybari, T., Hatamzadeh, N., Fattahi, M., Gharibnavaz, H., Khashij, S., \& Mahboubi, M. (2018). Cognitive determinants of influenza preventive behaviors among students: an application of the health belief model (HBM). International Journal of Pediatrics, 6(6), 7833-7841. https://doi.org/10.22038/ IJP.2017.27726.2399.

Ahmed, I., Qazi, T. F., \& Perji, K. A. (2011). Mobile phone to youngsters: Necessity or addiction. African Journal of Business Management, 32(5), 229-238.

Alabdulwahab, S. S., Kachanathu, S. J., \& AlMotairi, M. S. (2017). Smartphone use addiction can cause neck disability. Musculoskeletal Care, 15(1), 10-12. https://doi.org/10.1002/msc.1170.

Aletraris, L., Paino, M., Edmond, M. B., Roman, P. M., \& Bride, B. E. (2014). The use of art and music therapy in substance abuse treatment programs. Journal of addictions nursing, 25(4), 190-196. https://doi.org/10.1097/JAN.000000 0000000048.

Austin, M. P., Frilingos, M., Lumley, J., Hadzi-Pavlovic, D., Roncolato, W., Acland, S., Sainta, K., Segala, N., \& Parker, G. (2008). Brief antenatal cognitive behaviour therapy group intervention for the prevention of postnatal depression and anxiety: a randomised controlled trial. Journal of affective disorders, 105(1-3), 35-44. https://doi.org/10.1016/j.jad.2007.04.001\.

Azam, M., Ali, A., Mattiullah, J., \& Perveen, N. (2020). Physical activity, sports participation, and smartphone addiction in adolescent students: A systematic review. Journal of Evidence-Based Psychotherapies, 20(1). https://doi.org/ 10.24193/jebp.2020.1.2.

Baker, F. A., Gleadhill, L. M., \& Dingle, G. A. (2007). Music therapy and emotional exploration: Exposing substance abuse clients to the experiences of non-druginduced emotions. The Arts in Psychotherapy, 34(4), 321-330. https://doi.org/ 10.1016/j.aip.2007.04.005.

Bandura, A. (1991). Social cognitive theory of self-regulation. Organizational behavior and human decision processes, 50(2), 248-287. https://doi.org/ 10.1016/0749-5978(91)90022-L.

Bartel, K. A., Gradisar, M., \& Williamson, P. (2015). Protective and risk factors for adolescent sleep: A meta-analytic review. Sleep Medicine Reviews, 21, 72-85. https://doi.org/10.1016/j.smrv.2014.08.002.

Bartel, K., Scheeren, R., \& Gradisar, M. (2019). Altering adolescents' pre-bedtime phone use to achieve better sleep health. Health communication, 34(4), 456462. https://doi.org/10.1080/10410236.2017.1422099.

Beard, C., Sawyer, A. T., \& Hofmann, S. G. (2012). Efficacy of attention bias modification using threat and appetitive stimuli: A meta-analytic review. Behavior Therapy, 43(4), 724-740. https://doi.org/10.1016/j.beth.2012.01.002.

Beidas, R. S., Mychailyszyn, M. P., Podell, J. L., \& Kendall, P. C. (2013). Brief cognitive-behavioral therapy for anxious youth: the inner workings. Cognitive 
and Behavioral Practice, 20(2), 134-146. https://doi.org/10.1016/j.cbpra.2012. 07.004

Bian, M., \& Leung, L. (2015). Linking loneliness, shyness, smartphone addiction symptoms, and patterns of smartphone use to social capital. Social science computer review, 33(1), 61-79. https://doi.org/10.1177/0894439314528779.

Billieux, J., Maurage, P., Lopez-Fernandez, O., Kuss, D. J., \& Griffiths, M. D. (2015). Can disordered mobile phone use be considered a behavioral addiction? An update on current evidence and a comprehensive model for future research. Current Addiction Reports, 2(2), 156-162. https://doi.org/10.1007/ s40429015-0054-y.

Borkenau, P., \& Liebler, A. (1993). Convergence of stranger ratings of personality and intelligence with self-ratings, partner ratings, and measured intelligence. Journal of Personality and Social Psychology, 65(3), 546-553. https://doi.org/ 10.1037/0022-3514.65.3.546.

$\mathrm{Bu}$, Y. L. (2014). [Effect of physical exercise on college students' mobile phone addiction]. Modern Preventive Medicine, 41(7), 1242-1244.

Chang, J., \& Nylund, D. (2013). Narrative and solution-focused therapies: A twentyyear retrospective. Journal of Systemic Therapies, 32(2), 72-88. https://doi.org/ 10.1521/jsyt.2013.32.2.72.

Chen, J. X., Hu, Y. M., Lv, H. Q., \& Long, X. J. (2017). Changes of brain gray matter density in college students with mobile phone addiction. Journal of Clinical Radiology, 36(10), 1391-1395. https://doi.org/10.13437/j.cnki.jcr.2017.10.003.

Chen, X., Lin, Y., \& Liu, Q. X. (2020). The impact of technological inference on adolescents' smartphone addiction: The role of core self-evaluation and psychological demand network satisfaction. Journal of Psychological Science, 43(2), 355-362. https://doi.org/10.16719/j.cnki.1671-6981.20200214.

Chen, Y., \& Yu, X. P. (2017). Experimental study on positive attention bias training to alleviate mobile phone addiction tendency of vocational college students. Vocational \& Technical Education Forum, 35, 74-78.

Chen, Y. X., Lou, J., Zhang, P., \& Liu, X. P. (2019). [Qualitative research on problematic social networks usage in college students]. Chinese Mental Health Journal, 33(2), 143-148. https://doi.org/10.3969/j.issn.1000-6729.2019.02.013.

China Internet Network Information Center. (2020). [The 47th China Statistical Report on Internet Development]. http://www.cac.gov.cn/2021-02/03/c 1613923423079314.htm.

Choi, J., Park, Y., Kim, H. E., Song, J., Lee, D., Lee, E., ..., \& Lee, Y. (2021). Daily life changes and life satisfaction among Korean school-aged children in the COVID-19 pandemic. International Journal of Environmental Research and Public Health, 18(6), 3324. https://doi.org/10.3390/ijerph18063324.

Choi, N. (2015). The Effects of a smartphone addiction education program for young adult females. International Journal of $u$-and e-Service, Science and Technology, 8(12), 277-284. https://doi.org/10.14257/ijunesst.2015.8.12.28.

Chóliz, M. (2012). Mobile-phone addiction in adolescence: the test of mobile phone dependence (TMD). Progress in Health Sciences, 2(1), 33-44. 
Cochrane, T., \& Bateman, R. (2010). Smartphones give you wings: Pedagogical affordances of mobile Web 2.0. Australasian Journal of Educational Technology, 26(1). https://doi.org/10.14742/ajet.1098.

Crawley, S. A., Kendall, P. C., Benjamin, C. L., Brodman, D. M., Wei, C., Beidas, R. S., ... Mauro, C. (2013). Brief cognitive-behavioral therapy for anxious youth: feasibility and initial outcomes. Cognitive and Behavioral Practice, 20(2), 123133. https://doi.org/10.1016/j.cbpra.2012.07.003.

Demirci, K., Akgönül, M., \& Akpinar, A. (2015). Relationship of smartphone use severity with sleep quality, depression, and anxiety in university students. Journal of behavioral addictions, 4(2), 85-92. https://doi.org/10.1556/2006. 4.2015.010.

Dewald-Kaufmann, J. F., Oort, F. J., \& Meijer, A. M. (2013). The effects of sleep extension on sleep and cognitive performance in adolescents with chronic sleep reduction: an experimental study. Sleep Medicine, 14(6), 510-517. https://doi.org/ 10.1016/j.sleep.2013.01.012.

D'Hondt, F., Billieux, J., \& Maurage, P. (2015). Electrophysiological correlates of problematic internet use: Critical review and perspectives for future research. Neuroscience \& Biobehavioral Reviews, 59, 64-82. https://doi.org/10.1016/j. neubiorev.2015.10.005.

Ding, D., \& Li, J. (2017). Smartphone overuse-A growing public health issue. Journal of Psychology \& Psychotherapy, 7(1), 289. https://doi.org/10.4172/ 2161-0487.1000289.

Ding, X. L., Zu, J., \& Zhang, X. K. (2018). The effects of inhibition control training in mobile phone dependency college students. Studies of Psychology and Behavior, 16(3), 342-348. https://doi.org/10.3969/j.issn.1672-0628.2018.03.009.

Fernandez, D. P., Kuss, D. J., \& Griffiths, M. D. (2020). Short-term abstinence effects across potential behavioral addictions: A systematic review. Clinical Psychology Review, 101828. https://doi.org/10.1016/j.cpr.2020.101828.

$\mathrm{Fu}, \mathrm{S}$., Chen, X., \& Zheng, H. (2021). Exploring an adverse impact of smartphone overuse on academic performance via health issues: A stimulus-organismresponse perspective. Behaviour \& Information Technology, 40(7). https://doi.org/ 10.1080/0144929X.2020.1716848.

Fung, X., Siu, A., Potenza, M. N., O'Brien, K. S., Latner, J. D., Chen, C. Y., Chen, I. H., \& Lin, C. Y. (2021). Problematic use of internet-related activities and perceived weight stigma in schoolchildren: A longitudinal study across different epidemic periods of COVID-19 in China. Frontiers in Psychiatry, 12, 675839. https://doi.org/10.3389/fpsyt.2021.675839.

Ge, R. K., Zhong, X. M., \& Chen, R. (2015). [Influence of exercise intervention on mobile phone dependence in university students]. Modern Preventive Medicine, 42(21), 3919-3921.

Ghaderi, N., Ahmadpour, M., Saniee, N., Karimi, F., Ghaderi, C., \& Mirzaei, H. (2017). Effect of education based on the Health Belief Model (HBM) on anemia preventive behaviors among Iranian girl students. International Journal of Pediatrics, 5(6), 5043-5052. https://doi.org/10.22038/ijp.2017. 22051.1844 . 
Gingerich, W. J., \& Eisengart, S. (2000). Solution-focused brief therapy: A review of the outcome research. Family process, 39(4), 477-498. https://doi.org/ 10.1111/j.1545-5300.2000.39408.x.

Gong, H. L., \& Xu, W. S. (2015). [A meta-analysis on the effectiveness of solutionfocused brief therapy]. Studies of Psychology and Behavior, 13(6), 799-803.

Gong, Y. P., Chen, Z., Xie, J. L., \& Xie, X. C. (2019). Phubbing: antecedents, consequences and functioning mechanisms. Advances in Psychological Science, 27(7), 1258-1267. https://doi.org/10.3724/SP.J.1042.2019.01258.

Grant, J. E., Lust, K., \& Chamberlain, S. R. (2019). Problematic smartphone use associated with greater alcohol consumption, mental health issues, poorer academic performance, and impulsivity. Journal of Behavioral Addictions, 8(2), 335-342. https://doi.org/10.1556/2006.8.2019.32.

Griffiths, M. (2005). A 'components' model of addiction within a biopsychosocial framework. Journal of Substance Use, 10(4), 191-197. https://doi.org/10.1080/ 14659890500114359.

Guo, N., Wang, M. P., Luk, T. T., Ho, S. Y., Fong, D. Y. T., Chan, S. S. C., \& Lam, T. H. (2019). The association of problematic smartphone use with family wellbeing mediated by family communication in Chinese adults: A populationbased study. Journal of Behavioral Addictions, 8(3), 412-419. https://doi.org/ 10.1556/2006.8.2019.39.

Gupta, K., \& DSilva, M. H. (2020). Proliferation of social media during the COVID19 pandemic: a statistical enquiry. Journal of Xi'an University of Architecture \& Technology, XII(V), 1752-1759.

Gustafson, D. H., Boyle, M. G., Shaw, B. R., Isham, A., McTavish, F., Richards, S., Schubert, C., Levy, M., \& Johnson, K. (2011). An e-health solution for people with alcohol problems. Alcohol Research \& Health, 33(4), 327-337. https://www.researchgate.net/publication/234071174.

Han, J. F., Nie, J., \& Lei, P. F. (2018). [Psychological and physical intervention to mobile phone dependence among adolescents: A meta-analysis]. Chinese Journal of Health Education, 34(12), 1110-1114. https://doi.org/10.16168/ j.cnki.issn.1002-9982.2018.12.012.

Han., T., Ma., W. D., M. A., Gong., H., Hu, Y. C., Zhang, Y., Zhang, C. Y., Yao, Z. H., Fan, Y. J., Zheng, Y., \& Wang, C. X. (2021). Investigation and analysis of negative emotion among university students during home quarantine of COVID-19. Journal of Xi'an Jiaotong University (Medical Sciences), 42(1), 132-136. https://doi.org/10.7652/jdyxb202101025.

Haug, S., Castro, R. P., Kwon, M., Filler, A., Kowatsch, T., \& Schaub, M. P. (2015). Smartphone use and smartphone addiction among young people in Switzerland. Journal of Behavioral Addictions, 4(4), 299-307. https://doi.org/ 10.1556/2006.4.2015.037.

Hidayati, D. S. (2019). Smartphone addiction and loneliness in adolescent. In Proceedings of the 4th ASEAN Conference on Psychology, Counselling, and Humanities (ACPCH 2018), Paris.

Hofmann, S. G., Asnaani, A., Vonk, I. J., Sawyer, A. T., \& Fang, A. (2012). The efficacy of cognitive behavioral therapy: A review of meta-analyses. Cognitive 
Therapy and Research, 36(5), 427-440. https://doi.org/10.1007/s10608-0129476-1.

Hohmann, L., Bradt, J., Stegemann, T., \& Koelsch, S. (2017). Effects of music therapy and music-based interventions in the treatment of substance use disorders: A systematic review. PloS one, 12(11), e0187363. https://doi.org/ 10.1371/journal.pone. 0187363 .

Horvath, J., Mundinger, C., Schmitgen, M. M., Wolf, N. D., Sambataro, F., Hirjak, D., Kubera, K. M., Koenigde, J., \& Wolf, R. C. (2020). Structural and functional correlates of smartphone addiction. Addictive Behaviors, 105, 106334. https://doi.org/10.1016/j.addbeh.2020.106334.

Hu, X. P., \& Xie Z. X. (2020). On the advantages and challenges of online teaching $\&$ learning in universities \& colleges under the epidemic. China Higher Education Research, 4, 18-22. https://doi.org/10.16298/j.cnki.1004-3667. 2020.04.04.

Huang, J., Zheng, Y., Gao, D., Hu, M., \& Yuan, T. (2020). Effects of exercise on depression, anxiety, cognitive control, craving, physical fitness and quality of life in methamphetamine-dependent patients. Frontiers in Psychiatry, 10(January), 1-7. https://doi.org/10.3389/fpsyt.2019.00999.

Huang, Z. H., Tan., J. Y., Xu., H. F., Huang, B. Y., Chen, Q. S., Li, Z. W., Zhang, W. M., Zhang, Y. B., \& Gao, Y. H. (2021). [Association of smartphone addiction with daily behaviors and mental health during the COVID-19 pandemic among medical college students]. Chinese Journal of School Health, 42(5), 723-718. https://doi.org/10.16835/j.cnki.1000-9817.2021.05.018.

İNal, E. E., Demirci, K., Çetintürk, A., Akgönül, M., \& Savaş, S. (2015). Effects of smartphone overuse on hand function, pinch strength, and the median nerve. Muscle \& Nerve, 52(2), 183-188. https://doi.org/10.1002/mus.24695.

Jameel, S., Shahnawaz, M. G., \& Griffiths, M. D. (2019). Smartphone addiction in students: A qualitative examination of the components model of addiction using face-to-face interviews. Journal of Behavioral Addictions, 1-14. https://doi.org/10.1556/2006.8.2019.57.

Jeihooni, A. K., Arameshfard, S., Hatami, M., Mansourian, M., Kashfi, S. H., Rastegarimehr, B., Safari, O., \& Amirkhani, M. (2018). The effect of educational program based on health belief model about HIV/AIDS among high school students. International Journal of Pediatrics, 6(3), 7285-7296. https://doi.org/10.22038/ijp.2017.27226.2343.

Jia, J., Li, D., Li, X., Zhou, Y., Wang, Y., Sun, W., \& Zhao, L. (2018). Peer victimization and adolescent Internet addiction: The mediating role of psychological security and the moderating role of teacher-student relationships. Computers in Human Behavior, 85, 116-124. https://doi.org/ 10.1016/j.chb. 2018.03.042.

Jiang, Y. Z., Bai, X. L., \& Qi, S. S. (2020). Study of mindfulness based cognitive therapy on the problematic mobile social network usage of college students. Chinese Health Service Management, 37(3), 219-223.

Jun, S. (2016). The reciprocal longitudinal relationships between mobile phone addiction and depressive symptoms among Korean adolescents. Computers \& Human Behavior, 58, 179-186. https://doi.org/ 10.1016/j.chb.2015.12.061. 
Kayis, A. R., Satici, B., Deniz, M. E., Satici, S. A., \& Griffiths, M. D. (2021). Fear of COVID-19, loneliness, smartphone addiction, and mental wellbeing among the Turkish general population: a serial mediation model. Behaviour \& Information Technology, 1-13. https://doi.org/10.1080/0144929X.2021.1933181.

Keller, K., López, S. R., \& Moreno, M. M. C. (2015). Association between meal intake behaviour and abdominal obesity in Spanish adults. Appetite, 92, 1-6. https://doi.org/10.1016/j.appet.2015.04.077.

Kim, H. (2013). Exercise rehabilitation for smartphone addiction. Journal of Exercise Rehabilitation, 9(6), 500-505. https://doi.org/10.12965/jer.130080.

Kim, T. H., Jun, Y. S., Shin, Y. T., Lim, S. H., \& Seo, J. W. (2018). A preliminary study on the effectiveness of the peer relationship enhancement program in adolescents at risk for internet and smartphone addiction. Journal of the Korean Academy of Child and Adolescent Psychiatry, 29(2), 40-46. https://doi.org/ 10.5765/jkacap.2018.29.2.40.

Koo, H. Y. (2011). Development and effects of a prevention program for cell phone addiction in middle school students. Journal of Korean Academy of Child Health Nursing, 17(2), 91-99. https://doi.org/10.4094/jkachn.2011.17.2.91.

Khoshgoftar, M., Amidi Mazaheri, M., \& Tarrahi, M. J. (2019). The effect of educational intervention based on health belief model to decrease and prevent mobile phone addiction among female high school students in Iran. International Journal of Pediatrics, 7(10), 10175-10187. https://doi.org/ 10.22038/ijp.2019.40785.3438.

Ko, M., Choi, S., Yang, S., Lee, J., \& Lee, U. (2015). FamiLync: Facilitating participatory parental mediation of adolescents' smartphone use. In Proceedings of the 2015 ACM International Joint Conference on Pervasive and Ubiquitous Computing, 867-878. https://doi.org/10.1145/2750858.2804283.

Ko, M., Choi, S., Yatani, K., \& Lee, U. (2016). Lock n' LoL: Group-based limiting assistance app to mitigate smartphone distractions in group activities. In Proceedings of the 2016 CHI Conference on Human Factors in Computing Systems, 998-1010. https://doi.org/10.1145/2858036.2858568.

Ko, M., Yang, S., Lee, J., Heizmann, C., Jeong, J., Lee, U., Shin, D., Yatani, K., Song, J., \& Chung, K. M. (2015). NUGU: A group-based intervention app for improving self-regulation of limiting smartphone use. In Proceedings of the 18th ACM Conference on Computer Supported Cooperative Work \& Social Computing, 1235-1245. https://doi.org/10.1145/2675133.2675244.

Koelsch, S. (2009). A neuroscientific perspective on music therapy. Ann. NY Acad. Sci., 1169, 374-384. https://doi.org/10.1111/j.1749-6632.2009.04592.x.

Körmendi, A., Brutoczki, Z., Vegh, B. P., \& Szekely, R. (2016). Smartphone use can be addictive? A case report. Journal of behavioral addictions, 5(3), 548-552. https://doi.org/10.1556/2006.5.2016.033.

Kwon, M., Lee, J. Y., Won, W. Y., Park, J. W., Min, J. A., Hahn, C., Gu, X., Choi, J. H., \& Kim, D. J. (2013). Development and validation of a smartphone addiction scale (SAS). PloS one, 8(2), e56936. https://doi.org/10.1371/journal. pone. 0056936 . 
Lan, Y., Ding, J. E., Li, W., Li, J., Zhang, Y., Liu, M., \& Fu, H. (2018). A pilot study of a group mindfulness-based cognitive-behavioral intervention for smartphone addiction among university students. Journal of Behavioral Addictions, 7(4), 1171-1176. https://doi.org/10.1556/2006.7.2018.103.

Lan, Y. K., Ding, J. E., Zhu, X. Y., Jia, Y. N., Li, J., \& Fu, H. (2019). A review of the mobile phone addiction research. Chinese Journal of Disease Control \& Prevention, 23(11), 1328-1333. https://doi.org/10.16462/j.cnki.zhjbkz.2019. 11.006.

Lawrence, N. S., O'Sullivan, J., Parslow, D., Javaid, M., Adams, R. C., Chambers, C. D., Kosc, K., \& Verbruggen, F. (2015). Training response inhibition to food is associated with weight loss and reduced energy intake. Appetite, 95(1), 1728. https://doi.org/10.1016/j.appet.2015.06.009.

Lee, D., Namkoong, K., Lee, J., Lee, B. O., \& Jung, Y. C. (2019). Lateral orbitofrontal gray matter abnormalities in subjects with problematic smartphone use. Journal of behavioral addictions, 8(3), 404-411. doi:10.1556/ 2006.8.2019.50.

Lee, H., Ahn, H., Choi, S., \& Choi, W. (2014). The SAMS: Smartphone addiction management system and verification. Journal of Medical Systems, 38(1), 1-10. https://doi.org/10.1007/s10916-013-0001-1.

Leeman, R. F., Robinson, C. D., Waters, A. J., \& Sofuoglu, M. (2014). A critical review of the literature on attentional bias in cocaine use disorder and suggestions for future research. Experimental and Clinical Psychopharmacology, 22(6), 469-483. https://doi.org/10.1037/a0037806.

Lerma, A., Perez-Grovas, H., Bermudez, L., Peralta-Pedrero, M. L., Robles-García, R., \& Lerma, C. (2016). Brief cognitive behavioural intervention for depression and anxiety symptoms improves quality of life in chronic haemodialysis patients. Psychology and Psychotherapy: Theory, Research and Practice, 90(1), 105-123. https://doi.org/10.1111/papt.12098.

Li, L., Niu, Z. M., \& Mei, S. L. (2017). The mindfulness cognitive-behavioral group therapy of medical student' smartphone addiction in group counseling course. China Higher Medical Education, 5, 37-38. https://doi.org/10.3969/j.issn. 1002-1701.2017.05.016.

Li, N., \& Shi, W. W. (2015). Intervention to gambling addiction: A review of the literature. Journal of Capital University of Physical Education and Sports, 27(6), 558-562. https://doi.org/10.14036/j.cnki.cn11-4513.2015.06.017.

Liu, Q. Q., Zhou, Z. K., Yang, X. J., Kong, F. C., Niu, G. F., \& Fan, C. Y. (2017). Mobile phone addiction and sleep quality among Chinese adolescents: A moderated mediation model. Computers in Human Behavior, 72, 108-114. https://doi.org/10.1016/j.chb.2017.02.042.

Liu, X., Luo, Y., Liu, Z. Z., Yang, Y., Liu, J., \& Jia, C. X. (2020). Prolonged mobile phone use is associated with poor academic performance in adolescents. Cyberpsychology, Behavior, and Social Networking, 23(5), 303-311. https://doi.org/10.1089/cyber.2019.0591.

Liu, X. X., Wang, S., Zhou, J. Y., \& Cai, H. Q. (2020). Attention bias training for reducing smartphone addiction in Chinese college students. Journal of 
Evidence-Based Psychotherapies, 20(1), 1-24. https://doi.org/10.24193/ jebp.2020.1.1.

Long, J., Liu, T. Q., Liao, Y. H., Qi, C., He, H. Y., Chen, S. B., \& Billieux, J. (2016). Prevalence and correlates of problematic smartphone use in a large random sample of Chinese undergraduates. BMC psychiatry, 16(1), 408. https://doi.org/ 10.1186/s12888-016-1083-3.

Lopez-Fernandez, O. (2017). Short version of the smartphone addiction scale adapted to Spanish and French: Towards a cross-cultural research in problematic mobile phone use. Addictive Behaviors, 64, 275-280. https://doi.org/10.1016/ j.addbeh.2015.11.013.

Lopez-Fernandez, O., Honrubia-Serrano, L., Freixa-Blanxart, M., \& Gibson, W. (2014). Prevalence of problematic mobile phone use in British adolescents. Cyberpsychology, Behavior and Social Networking, 17(2), 91-98. https://doi.org/10.1089/cyber.2012.0260.

Luquis, R. R., \& Kensinger, W. S. (2019). Applying the health belief model to assess prevention services among young adults. International Journal of Health Promotion and Education, 57(1), 37-47. https://doi.org/10.1080/14635240. 2018.1549958.

Mac Cárthaigh, S. (2020). The effectiveness of interventions to reduce excessive mobile device usage among adolescents: a systematic review. Neurology, Psychiatry and Brain Research, 35, 29-37. https://doi.org/10.1016/j.npbr. 2019.11.002.

MacLeod, C., \& Clarke, P. J. F. (2015). The attentional bias modification approach to anxiety intervention. Clinical Psychological Science, 3(1), 58-78. https://doi.org/10.1177/2167702614560749.

Mahmoodi, H., Nadrian, H., Shaghaghi, A., Jafarabadi, M. A., Ahmadi, A., \& Saqqezi, G. S. (2018). Factors associated with mental health among high school students in Iran: Does mobile phone overuse associate with poor mental health? Journal of Child and Adolescent Psychiatric Nursing, 31(1), 6-13. https://doi.org/10.1111/jcap.12202.

Manning, V., Mroz, K., Garfield, J. B., Staiger, P. K., Hall, K., Lubman, D. I., \& Verdejo-Garcia, A. (2019). Combining approach bias modification with working memory training during inpatient alcohol withdrawal: an open-label pilot trial of feasibility and acceptability. Substance abuse treatment, prevention, and policy, 14(1), 24. https://doi.org/10.1186/s13011-019-0209-2.

Milde-Busch, A., von Kries, R., Thomas, S., Heinrich, S., Straube, A., \& Radon, K. (2010). The association between use of electronic media and prevalence of headache in adolescents: results from a population-based cross-sectional study. BMC neurology, 10(1), 12. https://doi.org/10.1186/1471-2377-10-12.

Mohammadbeigi, A., Absari, R., Valizadeh, F., Saadati, M., Sharifimoghadam, S., Ahmadi, A., Mokhtari, M., \& Ansari, H. (2016). Sleep quality in medical students; the impact of over-use of mobile cell-phone and social networks. Journal of research in health sciences, 16(1), 46-50. http://journals.umsha.ac. ir/index.php/JRHS/article/view/2484/pdf. 
Montag, C., Wegmann, E., Sariyska, R., Demetrovics, Z., \& Brand, M. (2021). How to overcome taxonomical problems in the study of Internet use disorders and what to do with "smartphone addiction"? Journal of Behavioral Addictions, 9(4), 908-914. https://doi.org/10.1556/2006.8.2019.59.

Neophytou, E., Manwell, L. A., \& Eikelboom, R. (2019). Effects of excessive screen time on neurodevelopment, learning, memory, mental health, and neurodegeneration: a scoping review. International Journal of Mental Health and Addiction, 19, 1-21. https://doi.org/10.1007/s11469-019-00182-2.

Nie, L., \& Liu, Y. L. (2014). The analysis and prevention of mobile phone dependency syndrome among college students. Modern Preventive Medicine, 41(2), 270-276.

Nylund, R., \& Leszczynski, D. (2006). Mobile phone radiation causes changes in gene and protein expression in human endothelial cell lines and the response seems to be genome-and proteome-dependent. Proteomics, 6(17), 4769-4780. https://doi.org/10.1002/pmic.200600076.

Okajima, I. (2015). Self-help intervention delivered via devices. Nihon rinsho. Japanese journal of clinical medicine, 73(6), 1006-1009. http://europepmc.org/ article/MED/26065133.

Panova, T., \& Carbonell, X. (2018). Is smartphone addiction really an addiction? Journal of Behavioral Addictions, 7(2), 252-259. https://doi.org/10.1556/2006. 7.2018.49.

Park, K. A., Kim, H. S., Lee, H. J., \& Kim, O. H. (2009). The effect of family and personal variable of internet addicted young adults. Korea J Health Psychol, 14(14), 41-51. https://doi.org/10.17315/kjhp.2009.14.1.003.

Park, S. Y., Kim, S. M., Roh, S., Soh, M. A., Lee, S. H., Kim, H., Lee, Y. S., \& Han, D. H. (2016). The effects of a virtual reality treatment program for online gaming addiction. Computer Methods and Programs in Biomedicine, 129, 99108. https://doi.org/10.1016/j.cmpb.2016.01.015.

Pelletier, C. L. (2004). The effect of music on decreasing arousal due to stress: A metaanalysis. Journal of Music Therapy, 41(3), 192-214. https://doi.org/10.1093/ jmt/41.3.192.

Piper, B. J., Daily, S. M., Martin, S. L., \& Martin, M. W. (2020). Evaluation of a brief intervention to reduce cell phone use. Preprints, 2020010137. https://doi.org/10.20944/preprints202001.0137.v1.

Redmayne, M., Smith, E., \& Abramson, M. J. (2011). Adolescent in-school cellphone habits: a census of rules, survey of their effectiveness, and fertility implications. Reproductive Toxicology, 32(3), 354-359. https://doi.org/10.1016/ j.reprotox.2011.08.006.

Riper, H., Andersson, G., Hunter, S. B., de Wit, J., Berking, M., \& Cuijpers, P. (2014). Treatment of comorbid alcohol use disorders and depression with cognitive-behavioural therapy and motivational interviewing: A meta-analysis. Addiction, 109(3), 394-406. https://doi.org/10.1111/add.12441.

Ross, S., Cidambi, I., Dermatis, H., Weinstein, J., Ziedonis, D., Roth, S., \& Galanter, M. (2008). Music therapy: a novel motivational approach for dually diagnosed 
patients. Journal of addictive diseases, 27(1), 41-53. https://doi.org/10.1300/ J069v27n01 05.

Rozgonjuk, D., Saal, K., \& Täht, K. (2018). Problematic smartphone use, deep and surface approaches to learning, and social media use in lectures. International Journal of Environmental Research and Public Health, 15(1), 92. https://doi.org/ 10.3390/ijerph15010092.

Sánchez-Martínez, M., \& Otero, A. (2009). Factors associated with cell phone use in adolescents in the community of Madrid (Spain). CyberPsychology \& Behavior, 12(2), 131-137. https://doi.org/10.1089/cpb.2008.0164.

Santos, V., Egidio Nardi, A., \& Lucia Spear King, A. (2015). Treatment of internet addiction in patient with panic disorder and obsessive compulsive disorder: a case report. CNS \& Neurological Disorders-Drug Targets (Formerly Current Drug Targets-CNS \& Neurological Disorders), 14(3), 341-344. https://doi.org/ 10.2174/1871527314666150225123532.

Shan, Z., Deng, G., Li, J., Li, Y., Zhang, Y., \& Zhao, Q. (2013). Correlational analysis of neck/shoulder pain and low back pain with the use of digital products, physical activity and psychological status among adolescents in Shanghai. Plos one, 8(10), e78109. https://doi.org/10.1371/journal.pone.0078109.

Sharma, M. K., \& Palanichamy, T. S. (2018). Psychosocial interventions for technological addictions. Indian journal of psychiatry, 60(Suppl 4), 541. https://doi.org/10.4103/psychiatry. IndianJPsychiatry_40_18.

de Shazer, S. (1985). Keys to solution in brief therapy. New York: W. W. Norton. de Shazer, S. (1991). Putting difference to work. New York: W. W. Norton.

Shi, B. B., Zhu, Z. P., Jiang, J. L., \& Li, C. B. (2017). [A review of brief cognitive behavioral therapy in application to depressive disorder]. Chinese Mental Health Journal, 31(9), 670-676. https://doi.org/10.3969/j.issn.1000-6729. 2017.09.002.

Shonin, E., Van Gordon, W., \& Griffiths, M. D. (2014). Are there risks associated with using mindfulness for the treatment of psychopathology? Clinical Practice, 11(4), 389-392. https://doi.org/10.2217/cpr.14.23.

Shuman, J., Kennedy, H., DeWitt, P., Edelblute, A., \& Wamboldt, M. Z. (2016). Group music therapy impacts mood states of adolescents in a psychiatric hospital setting. The Arts in Psychotherapy, 49, 50-56. https://doi.org/ 10.1016/j.aip.2016.05.014.

Smetaniuk, P. (2014). A preliminary investigation into the prevalence and prediction of problematic cell phone use. Journal of Behavioral Addictions, 3(1), 41-53. https://doi.org/10.1556/JBA.3.2014.004.

Spierer, L., Chavan, C., \& Manuel, A. L. (2013). Training-induced behavioral and brain plasticity in inhibitory control. Frontiers in human neuroscience, 7, 427. https://doi.org/10.3389/fnhum.2013.00427.

Statista.com. (2021). Number of smartphone subscriptions worldwide from 2016 to 2026 (in millions).

Stevens, M. W., King, D. L., Dorstyn, D., \& Delfabbro, P. H. (2019). Cognitivebehavioral therapy for Internet gaming disorder: A systematic review and meta- 
analysis. Clinical psychology \& psychotherapy, 26(2), 191-203. https://doi.org/ 10.1002/cpp.2341.

Su, B., Yu, C., Zhang, W., Su, Q., Zhu, J., \& Jiang, Y. (2018). Father-child longitudinal relationship: parental monitoring and internet gaming disorder in Chinese adolescents. Frontiers in Psychology, 9, 95. https://doi.org/10.3389/ fpsyg.2018.00095.

Su, B. Y., Li, J. X., Ye, T. T., \& Zhang, W. (2014). New progresses in the treatment of adolescent internet addiction. Journal of Guangzhou University (Social Science Edition), 13(12), 23-29.

Sun, D., \& Jia, A. (2016). Impacts of cell phone use on driving safety and drivers' perception of risk. Journal of Modern Transportation, 24(2), 145-152. https://doi.org/10.1007/s40534-016-0102-x.

$\mathrm{Su}, \mathrm{D} .$, \& Li, L. (2011). Trends in the use of complementary and alternative medicine in the United States: 2002-2007. Journal of health care for the poor and underserved, 22(1), 296-310. https://doi.org/10.1353/hpu.2011.0002.

Torous, J., Jän Myrick, K., Rauseo-Ricupero, N., \& Firth, J. (2020). Digital mental health and COVID-19: Using technology today to accelerate the curve on access and quality tomorrow. JMIR mental health, 7(3), e18848. https://doi.org/10.2 $196 / 18848$.

Torous, J., \& Keshavan, M. (2020). COVID-19, mobile health and serious mental illness. Schizophrenia research, 218, 36-37. https://doi.org/10.1016/j.schres. 2020.04.013.

van Deursen, A. J. (2020). Digital inequality during a pandemic: Quantitative study of differences in COVID-19-related internet uses and outcomes among the general population. Journal of Medical Internet Research, 22(8), e20073. https://doi.org/10.2196/20073.

Van Gordon, W., Shonin, E., Dunn, T. J., Garcia-Campayo, J., Demarzo, M. M., \& Griffiths, M. D. (2017). Meditation awareness training for the treatment of workaholism: A controlled trial. Journal of behavioral addictions, 6(2), 212220. https://doi.org/10.1556/2006.6.2017.021.

Wang, H. B., Tao, Y. K., \& Xu, H. T. (2015). [Inhibition control characteristics in college students with different mobile phone addiction]. Chinese Mental Health Journal, 29(3), 226-229. https://doi.org/10.3969/j.issn.1000-6729. 2015.03.012.

Wang, R., Zhang, R. X., \& Kang, J. X. (2018). [Positive psychological intervention on college students with mobile phone addiction]. Modern Preventive Medicine, 45(9), 1653-1666.

Wang, X. T., \& Zhang, C. (2016). [A study on the effect of exercise intervention in mobile phone addiction medical students]. China Higher Medical Education, 7, 22-23. https://doi.org/10.3969/j.issn.1002-1701.2016.07.011.

Wang, Y., Wu, A. M., \& Lau, J. T. (2016). The health belief model and number of peers with internet addiction as inter-related factors of Internet addiction among secondary school students in Hong Kong. BMC Public Health, 16(1), 272. https://doi.org/10.1186/s12889-016-2947-7. 
Ward, A. F., Duke, K., Gneezy, A., \& Bos, M. W. (2017). Brain drain: The mere presence of one's own smartphone reduces available cognitive capacity. Journal of the Association for Consumer Research, 2(2), 140-154. https://doi.org/ $10.1086 / 691462$.

Wei, H., Zhou, Z. K., Zhang, Y. X., \& Ding, Q. (2018). Relationship between stress and Internet addiction: The moderating effects of family support and friend support. Studies of Psychology and Behavior, 16(2), 266-271.

World Health Organization. (2021, July 21). Coronavirus Disease (COVID-19) Advice for the Public. Retrieved from https://www.who.int/emergencies/ diseases/novel-coronavirus-2019/advice-for-public.

Xie, X., Dong, Y., \& Wang, J. (2018). Sleep quality as a mediator of problematic smartphone use and clinical health symptoms. Journal of Behavioral Addictions, 7, 466-472. https://doi.org/10.1556/2006.7.2018.40.

Xu, W. M., Liang, Q. S., Luo, S. M., \& Han, X. Q. (2017). [A comparative study of the solution-focused brief therapy in the treatment of college students with mobile phone addiction]. Chinese Journal of Special Education, 2, 78-83. https://doi.org/10.3969/j.issn.1007-3728.2017.02.014.

$\mathrm{Xu}, \mathrm{W}$. S. (2014). [Paradigm shift represents-solution focused brief therapy of the counseling philosophy]. Psychology: Techniques and Applications, 4, 41-44. https://doi.org/10.16842/j.cnki.issn2095-5588.2014.04.013.

Yang, Z., Asbury, K., \& Griffiths, M. D. (2019). An exploration of problematic smartphone use among Chinese university students: associations with academic anxiety, academic procrastination, self-regulation and subjective wellbeing. International Journal of Mental Health and Addiction, 17(3), 596614. https://doi.org/10.1007/s11469-018-9961-1.

Yen, C. F., Tang, T. C., Yen, J. Y., Lin, H. C., Huang, C. F., Liu, S. C., \& Ko, C. H. (2009). Symptoms of problematic cellular phone use, functional impairment and its association with depression among adolescents in Southern Taiwan. Journal of Adolescence, 32(4), 863-873. https://doi.org/10.1016/j.adolescence. 2008.10.006.

Young, K. (2009). Internet addiction: Diagnosis and treatment considerations. Journal of Contemporary Psychotherapy, 39(4), 241-246. https://doi.org/ 10.1007/s10879-009-9120-x.

Yu, Z. Y., \& Liu, W. (2019). [A meta-analysis of relation of smartphone use to anxiety, depression and sleep quality]. Chinese Mental Health Journal, 33(12), 938-943. https://doi.org/10.3969/j.issn.1000-6729.2019.12.010.

Zadeh, D. S., Changizi, M., \& Sadeghi, R. (2014). The effect of education about addiction through Health Belief Model (HBM) on knowledge and perceptions of high school students in Shadegan. 2017/May/20.

Zatorre, R. J. (2015). Musical pleasure and reward: mechanisms and dysfunction. Annals of the New York Academy of Sciences, 1337(1), 202-211. https://doi.org/ 10.1111/nyas. 12677.

Zhai, C., Gai, X. S., Jiao, X. Y., \& Yu, B. C. (2016). Mechanisms of cognitive transformation in mindfulness training. Journal of Northeast Normal University 
(Philosophy and Social Sciences), (2), 182-187. https://doi.org/10.16164/ j.cnki.22-1062/c.2016.02.032.

Zhang, M., Xiao, Q., \& Zhu, L. Y. (2019). [Research progress in mobile phone dependence: causes, outcomes and interventions]. Chinese Journal of Special Education, 11, 88-96.

Zhang, M. X., Chen, J. H., Tong, K. K., Yu, E. W. Y., \& Wu, A. (2021). Problematic smartphone use during the COVID-19 pandemic: Its association with pandemicrelated and generalized beliefs. International Journal of Environmental Research and Public Health, 18(11), 5724. https://doi.org/10.3390/ijerph18115724.

Zhang, X., Chen, L. X., \& Du, S. Z. (2016). [Teenagers' mobile phones depend on research progress at home and abroad]. Chinese Journal of School Health, 37(11), 1756-1760. https://doi.org/10.16835/j.cnki.1000-9817.2016.11.053

Zhang, X. X \& Zhu, H. X. (2014). The intervention effect of mindfulness-based cognitive therapy on college students with mobile phone addiction. Studies of Psychology and Behavior, 12(3), 391-394.

Zhao, G. M., Zhang, Z. Q., \& Guan, X. B. (2009). [Application of solution-focused brief counseling in sport psychology]. China Sport Science and Technology, 45(3), 61-67. https://doi.org/10.16470/j.csst.2009.03.014.

Zhao, Y. X., Hao., Y. H., \& Jing, X. Z. (2021). [Smartphone addiction intervention through sports combining with group psychological training among college students]. Chinese Journal of School Health, 42(4), 556-559. https://doi.org/ 10.16835/j.cnki.1000-9817.2021.04.018.

Zhen, R., Liu, R. D., Hong, W., \& Zhou, X. (2019). How do interpersonal relationships relieve adolescents' problematic mobile phone use? The roles of loneliness and motivation to use mobile phones. International journal of environmental research and public health, 16(13), 2286. https://doi.org/ 10.3390/ijerph16132286. 